\title{
Optimasi Produksi Hijab Menggunakan Program Linear Multi Objective Fuzzy
}

\author{
Rima Erfianti ${ }^{*}$, Muhammad Nizam Muhaijir $^{2}$ \\ 1,2 Jurusan Matematika, Fakultas Sains dan Teknologi, UIN Sultan Syarif Kasim Riau, \\ Jl. HR. Soebrantas Panam Km. 15 No. 155, Kota Pekanbaru 28293, Riau, Indonesia \\ * Penulis Korespondensi. Email: rima082016@gmail.com
}

\begin{abstract}
ABSTRAK
Beberapa penelitian tentang optimalisasi produksi sudah dilakukan, salah satu metode yang sering digunakan adalah metode simpleks. Namun, metode ini memiliki keterbatasan, diantaranya hanya dapat digunakan pada kasus yang memiliki satu fungsi tujuan. Metode yang dapat digunakan untuk kasus-kasus yang memiliki lebih dari satu fungsi tujuan adalah program linear multi objective fuzzy. Metode ini digunakan untuk mengoptimalisasi produksi hijab di Toko Latifah Hijab dengan menentukan jumlah yang tepat untuk setiap model dan memperoleh keuntungan yang maksimum. Berdasarkan penelitian diperoleh hasil perhitungan optimasi diantaranya jumlah hijab segi empat rimpel batik yang harus diproduksi sebanyak 320 buah, hijab pashmina instan sebanyak 6 buah, nilai variabel Lambda sebesar 0,58 yang menunjukkan derajat keanggotaan untuk setiap fungsi tujuan, keuntungan maksimum sebesar Rp 9.840 .000 serta waktu pengerjaan minimum adalah 6.500 menit.
\end{abstract}

Kata Kunci:

Optimasi; Hijab; Metode Simpleks; Program Linear; Multi Objective Fuzzy

\section{ABSTRACT}

There are some studies on the optimization of production have been introduced, one method that is often used is a simplex method. However, this method has limitations, including only being used in cases that have one objective function. The method that can be used for cases that have more than one objective function is a fuzzy multi-objective linear programming. This method is used to optimize the production of headscarves in the Latifah Hijab Store by determining the right amount for each model and obtaining maximum profits. 6 pieces, the variable value $\lambda$ of 0.58 which shows the level of participation for each objective function, the maximum profit of Rp. 9,840,000 and the minimum processing time is 6,500 minutes.

Keywords:

Optimization; Hijab; Simplex Method; Multi Objective Fuzzy; Linear Programming

Format Sitasi:

R. Erfianti and M.N. Muhaijir, "Optimasi Produksi Hijab Menggunakan Program Linear Multi Objective Fuzzy," Jambura J. Math., vol. 2, no. 1, pp.22-29, 2020

e-ISSN: 2656-1344 (C) 2020 R. Erfianti, M.N. Muhaijir | Under the license CC BY-NC 4.0

Diterima: 06 Juli 2019 | Disetujui: 01 November 2019 | Online: 31 Januari 2020 


\section{Pendahuluan}

Persaingan bisnis di Indonesia kini mengalami kemajuan begitu pesat, semakin bertambahnya perusahaan baru dari hari ke hari membuat dunia bisnis menjadi isu global yang hangat diperbincangkan. Mempertahankan dan meningkatkan daya saing suatu perusahaan membutuhkan perbaikan terus menerus dalam semua aspek kegiatan, agar dampak dari persaingan bisnis yang diantisipasi benar-benar tercapai, garis perbaikan harus konsisten dengan strategi yang dimiliki oleh pebisnis [1]. Salah satu strategi yang diterapkan perusahaan adalah perencanaan produksi barang maupun jasa yang efektif dan efisien.

Perencanaan suatu produksi memiliki peran penting dalam dunia industri, karena berkaitan dengan rencana perusahaan untuk memenuhi permintaan produk, laba, kualitas dan penggunaan sumber daya yang ada [2]. Kegiatan produksi tentunya memiliki tujuan untuk mengoptimumkan penggunaan bahan baku dengan memperoleh keuntungan maksimum, pengendalian terhadap persediaan bahan baku dalam suatu perusahaan sangat diperlukan agar kegiatan produksi dapat berjalan dengan baik dan terarah sesuai dengan target yang inginkan.

Terdapat beberapa penelitian yang berkaitan dengan optimalisasi suatu produksi menggunakan metode simpleks, seperti penelitian dalam [3][4]. Metode simpleks juga digunakan dalam [5] untuk mengoptimalisasi bahan baku pembuatan roti dengan fungsi tujuan memaksimumkan laba. Artikel serupa juga dapat dibaca pada [6] yang mengoptimalisasi campuran produk dari sebuah toko pakaian online dengan fungsi tujuan meminimumkan biaya pasokan. Akan tetapi, penggunaan metode simpleks memiliki keterbatasan, yakni hanya dapat digunakan pada kasus yang memiliki satu fungsi tujuan. Pada artikel ini digunakan metode baru yaitu Program Linear Multi Objective Fuzzy untuk mengoptimasi produksi hijab di Toko Latifah Hijab.

\section{Metode}

Metode yang digunakan dalam penelitian ini adalah program linear multi objective fuzzy dan penggunaannya dalam berbagai masalah optimasi produksi. Bahan penelitian diperoleh melalui studi literatur dengan mengumpulkan data dan informasi terhadap materi-materi yang berkaitan dengan penelitian yang bersumber dari beberapa artikel. Disamping studi literatur, penelitian ini juga menggunakan studi kasus dengan menggunakan data pada Toko Latifah Hijab.

\subsection{Pemrograman Linear}

Pemrograman linear mengidentifikasikan satu pemecahan dasar awal yang dibuat secara sistematis menjadi pemecahan dasar lainnya dan memperbaiki nilai fungsi tujuan. Model linear programming memiliki tiga komponen dasar yaitu variabel keputusan yang akan ditentukan, tujuan (goal) yang perlu dioptimalkan (memaksimalkan atau meminimalkan) dan kendala yang harus dipenuhi oleh solusi [7].

\subsection{Program Linear Multi Objective Fuzzy}

Program linear multi objective fuzzy adalah metode optimasi dengan beberapa fungsi tujuan yang tunduk pada beberapa batasan. Solusi permasalahan program linear multi objective fuzzy tidak diperoleh seperti penyelesaian optimasi dengan satu fungsi tujuan 
tetapi dengan mempertimbangkan dua tujuan [8]. Penyelesaian mengunakan program linear multi objective fuzzy pada artikel ini dilakukan dengan mengikuti langkah-langkah sebagai berikut:

Langkah pertama berkaitan dengan pengolahan data dilakukan dengan mengubah ke bentuk umum program linear, kemudian bentuk tersebut diubah menjadi bentuk standar metode simpleks. Perhitungan awal dilakukan sebanyak 2 kali yaitu pada saat tidak menggunakan angka toleransi $(t=0)$ dan pada saat menggunakan angka toleransi $(t=1)$. Model awal tanpa menggunakan angka toleransi persediaan ditunjukkan pada Persamaan (1), dengan fungsi tujuan memaksimumkan/ minimumkan

$$
\begin{gathered}
z_{1}(x)=c_{11} x_{1}+c_{12} x_{2}+\cdots+c_{1 n} x_{n}=c_{1} x \\
z_{2}(x)=c_{21} x_{1}+c_{22} x_{2}+\cdots+c_{2 n} x_{n}=c_{2} x \\
\vdots \\
z_{k}(x)=c_{k 1} x_{1}+c_{k 2} x_{2}+\cdots+c_{k n} x_{n}=c_{k} x
\end{gathered}
$$

dengan batasan

$$
\begin{array}{r}
A x \leq b \\
x \geq 0
\end{array}
$$

dengan

$$
\begin{aligned}
c_{i} & =\left(c_{i 1}, \ldots, c_{i n}\right) \\
i & =1,2, \ldots, k \\
x & =\left(x_{1}, \ldots, x_{n}\right)^{T} \text { dan } \\
A & =\left[a_{i j}\right], \text { matriks berukuran } m \times n .
\end{aligned}
$$

Misalkan $z_{i}(x)$ mempunyai fuzzy goal $r_{i}$, maka (1) menjadi program linear multi objective fuzzy, yaitu

dengan

$$
\begin{aligned}
c_{i} x & \geq r_{i} \\
A x & \leq b \\
x & \geq 0
\end{aligned}
$$

$$
\begin{aligned}
& b=\left(b_{1}, \ldots, b_{m}\right)^{T} \\
& r=\left(r_{1}, \ldots, r_{m}\right)^{T} .
\end{aligned}
$$

Selanjutnya, model awal yang diperoleh dari data dengan menambahkan angka toleransi persediaan ditunjukkan pada Persamaan (2) dengan fungsi tujuan memaksimumkan/minimumkan

$$
\begin{gathered}
z_{1}(x)=c_{11} x_{1}+c_{12} x_{2}+\cdots+c_{1 n} x_{n}=c_{1} x \\
z_{2}(x)=c_{21} x_{1}+c_{22} x_{2}+\cdots+c_{2 n} x_{n}=c_{2} x \\
\vdots \\
z_{k}(x)=c_{k 1} x_{1}+c_{k 2} x_{2}+\cdots+c_{k n} x_{n}=c_{k} x
\end{gathered}
$$

dengan batasan

$$
\begin{gathered}
A x \leq b+t \\
x \geq 0 .
\end{gathered}
$$

Pembentukan model selanjutnya dilakukan dengan mengubah fungsi tujuan pertama menjadi fungsi tujuan yang meminimumkan, diberikan pada Persamaan (3). 


$$
\begin{gathered}
-z_{1}(x)=-c_{11} x_{1}-c_{12} x_{2}-\cdots-c_{1 n} x_{n}=-c_{1} x \\
z_{2}(x)=c_{21} x_{1}+c_{22} x_{2}+\cdots+c_{2 n} x_{n}=c_{2} x \\
\vdots \\
z_{k}(x)=c_{k 1} x_{1}+c_{k 2} x_{2}+\cdots+c_{k n} x_{n}=c_{k} x .
\end{gathered}
$$

dengan batasan yang sama seperti formulasi model Persamaan (2).

Hasil perhitungan pada Persamaan (3) membentuk batasan fuzzy untuk kedua fungsi tujuan dengan fungsi keanggotaan pada himpunan ke- $i$ adalah $\mu_{i}\left[B_{i} x\right]$. Fungsi keanggotaan untuk model keputusan himpunan fuzzy ditunjukkan pada Persamaan (4).

$$
\mu_{D}[x]=\min _{i}\left\{\mu_{i}\left[B_{i} x\right]\right\}
$$

Berdasarkan fungsi keanggotaan tersebut diharapkan mendapat solusi terbaik, yaitu solusi dengan nilai keanggotaan yang paling besar. Dengan demikian, solusi yang optimum ditunjukkan pada Persamaan (5).

$$
\max _{x \geq 0} \mu_{D}\left[B_{i} x\right]=\max _{x \geq 0} \min _{i}\left\{\mu_{i}\left[B_{i} x\right]\right\}
$$

Mengacu pada Persamaan (5) dapat ditunjukkan bahwa $\mu_{i}\left(B_{i} x\right)=0$ jika batasan ke- $i$ benar-benar dilanggar. Sebaliknya $\mu_{i}\left(B_{i} x\right)=1$ jika batasan ke-i benar-benar dipatuhi (sama halnya dengan batasan bernilai tegas). Nilai $\mu_{i}\left(B_{i} x\right)$ mengikuti Persamaan (6) akan turun secara monoton pada selang $[0,1]$ sebagaimana ditunjukkan pada Gambar 1.

$$
\mu_{i}\left[B_{i} x\right]=\left\{\begin{array}{cl}
1 & \text { jika } B_{i} x \leq d_{i} \\
{[0,1]} & \text { jika } d_{i}<B_{i} \leq d_{i}+p_{i} \\
0 & \text { jika } B_{i} x>d_{i}+p_{i}
\end{array}\right.
$$

dengan $i=0,1,2, \ldots, m$.

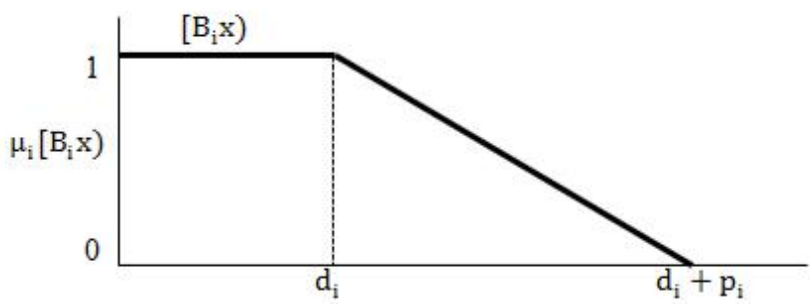

Gambar 1. Fungsi keanggotaan

Gambar 1 menunjukkan fungsi keanggotaan yang turun secara monoton dengan $p_{i}$ adalah toleransi interval yang diperbolehkan untuk melakukan pelanggaran baik pada fungsi objektif maupun batasan. Dengan menyubstitusikan Persamaan (6) ke Persamaan (5), diperoleh

$$
\max _{x \geq 0}=\max _{x \geq 0} \min _{i}\left\{1-\frac{B_{i} x-d_{i}}{p_{i}}\right\}
$$

Misalkan $\lambda=\min \left\{\mu_{i}\left[B_{i} x\right]\right\}$, maka diperoleh bentuk program linear baru dengan fungsi tujuan memaksimumkan $\lambda$, dengan Batasan $\lambda \leq \mu_{i}\left[B_{i} x\right]$ dan $x \geq 0$ dengan $i=0,1,2, \ldots$. 


\section{Hasil dan Pembahasan}

Data yang digunakan dalam penelitian ini merupakan data primer dari sebuah usaha mandiri yang memproduksi hijab. Terdapat dua jenis produk yang digunakan dalam penelitian ini yaitu hijab segiempat rimpel batik sebagai produk pertama dan hijab pashmina instan sebagai produk kedua. Keseluruhan bahan dalam pembuatan hijab segi empat rimpel batik dan hijab pashmina instan yaitu kain diamond, benang, kain batik, dan pet antem. Data kebutuhan, persediaan, toleransi, keuntungan dan waktu pengerjaan disajikan pada Tabel 1.

Tabel 1. Data produksi hijab di toko Latifah Hijab tahun 2019

\begin{tabular}{ccccc}
\hline Bahan & $\begin{array}{c}\text { Hijab Segiempat } \\
\text { (Rimpel Batik) }\end{array}$ & $\begin{array}{c}\text { Hijab Pashmina } \\
\text { (Instan) }\end{array}$ & Persediaan & $\begin{array}{c}\text { Toleransi } \\
\text { Persediaan }\end{array}$ \\
\hline $\begin{array}{c}\text { Kain Diamond } \\
\text { (Berbagai Warna) }\end{array}$ & $1,30 \mathrm{~m}$ & $2,00 \mathrm{~m}$ & $350 \mathrm{~m}$ & $200 \mathrm{~m}$ \\
$\begin{array}{c}\text { Benang } \\
\text { (Warna-Warni) }\end{array}$ & $2,50 \mathrm{~m}$ & $2,50 \mathrm{~m}$ & $525 \mathrm{~m}$ & $300 \mathrm{~m}$ \\
Kain Batik & $1,00 \mathrm{~m}$ & - & $750 \mathrm{~m}$ & $500 \mathrm{~m}$ \\
Pet Antem & - & 1,00 & $350 \mathrm{pet}$ & $250 \mathrm{pet}$ \\
Keuntungan & $30.000 /$ unit & $40.000 /$ unit & & - \\
Waktu Pengerjaan & 20 Menit/unit & 30 Menit/unit & - & \\
\hline
\end{tabular}

Pengolahan data dilakukan dengan menggunakan Software POM-QM for Windows. Misalkan $x_{1}=$ Hijab Rimpel Batik Segiempat dan $x_{2}=$ Hijab Instan Pashmina. Dengan mengacu pada Persamaan (1) dan menggunakan data pada Tabel 1, diperoleh model awal tanpa menggunakan angka toleransi persediaan yaitu

Maksimumkan: $z_{1}=30.000 x_{1}+40.000 x_{2} \quad$ (Keuntungan)

Minimumkan: $z_{2}=20 x_{1}+30 x_{2} \quad$ (Waktu Pengerjaan)

dengan batasan

$\begin{array}{cl}1,3 x_{1}+2 x_{2} & \leq 350 \\ 2,5 x_{1}+2,5 x_{2} & \leq 525 \\ x_{1} & \leq 750 \\ x_{2} & \leq 350 \\ x_{1}, x_{2} & \geq 0\end{array}$

Hasil perhitungan dari model awal di atas untuk nilai $t=1$, menghasilkan $x_{1}=$ $100, x_{2}=110, z_{1}=7.400 .000$, dan $z_{2}=5.300$. Selanjutnya, berdasarkan model pada Persamaan (2) dengan menggunakan angka toleransi persediaan memberikan model berikut,

Maksimumkan: $z_{1}=30.000 x_{1}+40.000 x_{2}$ (Keuntungan)

Minimumkan: $z_{2}=20 x_{1}+30 x_{2} \quad$ (Waktu Pengerjaan)

dengan batasan,

$$
\begin{aligned}
& 1,3 x_{1}+2 x_{2} \leq 350+200 t \\
& 2,5 x_{1}+2,5 x_{2} \leq 525+300 t
\end{aligned}
$$




$\begin{array}{ccc}x_{1} & \leq & 750+500 t \\ x_{2} & \leq & 350+250 t \\ x_{1}, x_{2} & \geq & 0\end{array}$

Hasil perhitungan menghasilkan $x_{1}=157, x_{2}=173, z_{1}=11.628 .570$ dan $z_{2}=8.328,6$. Kemudian berdasarkan Persamaan (3) fungsi tujuan pertama menjadi:

Minimumkan: $-z_{1}=-30.000 x_{1}-40.000 x_{2} \quad$ (Keuntungan)

Minimumkan: $z_{2}=20 x_{1}+30 x_{2} \quad$ (Waktu Pengerjaan)

Dengan batasan yang sama seperti formulasi model sebelumnya dan mengacu pada Persamaan (6), diperoleh fungsi keanggotaan setiap fungsi tujuan, ditunjukkan pada Gambar 2.
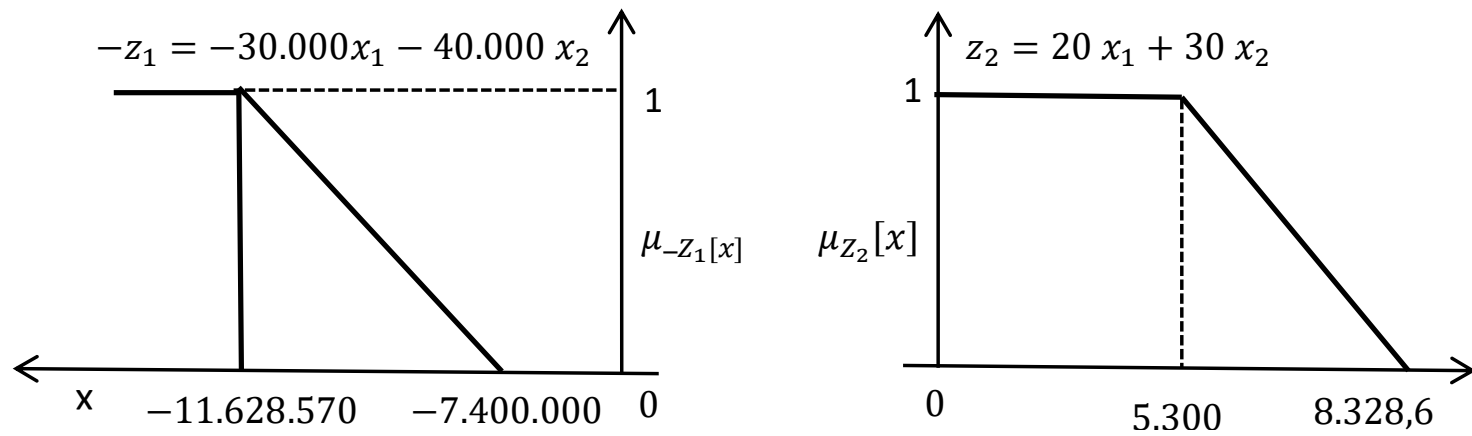

Gambar 2. Fungsi keanggotaan masing-masing tujuan

Selanjutnya dibentuk model baru yaitu dengan tujuan memaksimumkan $\lambda$ dan menambahkan kedua fungsi tujuan menjadi fungsi pembatas, sehingga 4 fungsi pembatas awal bertambah menjadi 6 fungsi pembatas. Model baru yang diperoleh adalah sebagai berikut:

Maksimumkan

$\lambda$

dengan batasan

$\begin{array}{llc}-4228570 \lambda+30.000 x_{1}+40.000 x_{2} & \geq & 7.400 .000 \\ 3028,6 \lambda+20 x_{1}+30 x_{2} & \leq & 8.328,6 \\ 200 \lambda+1,3 x_{1}+2 x_{2} & \leq & 550 \\ 300 \lambda+2,5 x_{1}+2,5 x_{2} & \leq & 825 \\ 500 \lambda+x_{1} & \leq & 1250 \\ 250 \lambda+x_{2} & \leq & 600 \\ x_{1}, x_{2} & \geq & 0\end{array}$

Penyelesaian akhir dilakukan dengan menggunakan teknik dua fase karena terdapat satu fungsi pembatas yang memiliki tanda lebih besar atau sama dengan $(\geq)$. Hasil akhir dari optimasi produksi hijab disajikan pada Tabel 2. 
Tabel 2. Hasil akhir perhitungan model program linear Multi Objective Fuzzy

\begin{tabular}{cc}
\hline BV & Nilai Optimal \\
\hline$\lambda$ & 0,58 \\
$x_{1}$ & 320 \\
$x_{2}$ & 6 \\
$z_{1}$ & 9.840 .000 \\
$z_{2}$ & 6.500 \\
\hline
\end{tabular}

Berdasarkan Tabel 2, diperoleh hasil akhir nilai $x_{1}=320, x_{2}=6$, $z_{1}=9.840 .000$ dan $z_{2}=6.500$. Dengan memproduksi hijab jenis rimpel batik sebanyak 320 unit dan hijab pashmina instan sebanyak 6 unit, maka toko Latifah Hijab akan memperoleh keuntungan maksimum sebesar Rp. 9.840.000, dengan waktu pengerjaan minimum selama 6.500 menit dan nilai variabel $\lambda$ sebesar 0,58 yang menunjukkan derajat keanggotaan untuk setiap fungsi tujuan.

\section{Kesimpulan}

Optimasi produksi hijab segi empat rimpel batik dan hijab pashmina instan menggunakan program linear multi objective fuzzy mencapai tujuan yang lebih dari satu yaitu dengan memperoleh keuntungan maksimum dan waktu pengerjaan minimum. Kondisi optimal dapat diperoleh dengan produksi jumlah hijab segi empat rimpel batik sebanyak 320 unit, pashmina instan sebanyak 6 unit dengan keuntungan maksimum sebesar Rp. 9.840.000 dan waktu pengerjaan minimum selama 6.500 menit.

\section{Referensi}

[1] J. Lopatowska, "Improving the Production Planning and Control Process," J. Manag. Financ., vol. 13, no. 4, pp. 119-130, 2015.

[2] S. Anwar and A. Lonny, "Optimization of Production Planning Using Goal Programming Method (A Case Study in a Cement Industry)," Int. J. Appl. Math. Electron. Comput., vol. 3, no. 5, pp. 90-95, 2015.

[3] M. Nabasirye, J. Y. T. Mugisha, F. Tibayungwa, and C. C. Kyarisiima, “Optimization of Input in Animal Production: A Linear Programming Approach to the Ration Formulation Problem," Int. Res. J. Agric. Sci. Soil Sci., vol. 1, no. 7, pp. 221-226, 2011.

[4] O. S. Balogun, E. T. Jolayemi, T. J. Akingbade, and H. G. Muazu, “Use of Linear Programming for Optimal Production in A Production Line in Coca-Cola Bottling Company," Int. J. Eng. Res. Appl., vol. 2, no. 5, pp. 2004-2007, 2012.

[5] N. Akpan and I. A. Iwok, "Aplication of Linear Programming for Optimal Use of Raw Materials in Bakery," Int. J. Math. Stat. Invent., vol. 4, no. 8, pp. 51-57, 2016.

[6] M. Molina, "Produk Mix Optimization at Minimum Supply Cost of an Online Clothing Store Using Linear Programming," in The International Conference on Mathematics, Science, Education, and Technology (ICOMSET), 2018, pp. 33-38.

[7] H. A. Taha, Operations Research: An Introduction, 8th ed. New York: Pearson Prentice Hall, 2007. 
Optimasi Produksi Hijab Menggunakan Program Linear Multi Objective Fuzzy

[8] M. Sakawa, Fuzzy Sets and Interactive Multiobjective Optimization. New York: Springer, 1993. 